\title{
Role of poly(ADP-ribose) polymerase activity in imatinib mesylate-induced cell death
}

\author{
A Moehring ${ }^{1}$, L Wohlbold ${ }^{1}$, WE Aulitzky ${ }^{2}$ and $\mathrm{H}$ van der Kuip ${ }^{\star, 1}$ \\ ${ }^{1}$ Dr. Margarete Fischer-Bosch Institute of Clinical Pharmacology, Auerbachstr. \\ 112, Stuttgart, Germany \\ 2 2nd Department of Internal Medicine, Oncology and Hematology, Robert \\ Bosch Hospital, Auerbachstr. 110, Stuttgart, Germany \\ * Corresponding author: $\mathrm{H}$ van der Kuip, Dr. Margarete Fischer-Bosch Institute \\ of Clinical Pharmacology, Auerbachstr. 112, 70376 Stuttgart, Germany. \\ Tel: + 49711 81013730; fax: + 49711859295 ; \\ E-mail: heiko.van-der-kuip @ikp-stuttgart.de
}

Received 17.11.04; revised 10.1.05; accepted 02.2.05; published online 01.4.05 Edited by JA Cidlowski

\begin{abstract}
Imatinib targets Bcr-Abl, the causative event of chronic myelogenous leukemia (CML), and addresses leukemic cells to growth arrest and cell death. The exact mechanisms responsible for imatinib-induced cell death are still unclear. We investigated the role of poly(ADP-ribose) polymerase (PARP) activity in imatinib-induced cell death in Bcr-Ablpositive cells. Imatinib leads to a rapid increase of poly(ADPribosyl)ation (PAR) preceding loss of integrity of mitochondrial membrane and DNA fragmentation. The effect of imatinib on PAR can be mimicked by inhibition of phosphatidylinositol 3kinase (PI3-K) implicating a central role of the PI3-K pathway in Bcr-Abl-mediated inhibition of PAR. Importantly, inhibition of PAR in imatinib-treated cells partially prevented cell death to an extent comparable to that observed after caspase inhibition. Simultaneous blockade of both caspases and PAR revealed additive cytoprotective effects indicating that both pathways function in parallel. In conclusion, our results suggest that in addition to the well-documented caspase-dependent pathway, imatinib also induces a PARP-mediated death process.

Cell Death and Differentiation (2005) 12, 627-636.

doi:10.1038/sj.cdd. 4401608

Published online 1 April 2005
\end{abstract}

Keywords: CML; Bcr-Abl kinase; imatinib mesylate (STI571, Gleevec ${ }^{\mathbb{R}}$ ); poly(ADP-ribose) polymerase (PARP)

Abbreviations: AIF, apoptosis-inducing factor; CML, chronic myelogenous leukemia; BA, bcr-abl; MAPK, mitogen-activated protein kinase; MEFs, mouse embryonic fibroblasts; MNNG, $N$ methyl- $N$-nitro- $N$-nitrosoguanidine; PARP, poly(ADP-ribose) polymerase; PAR, poly(ADP-ribosyl)ation; PI, propidium iodide; PI3-K, phosphatidylinositol 3-kinase; SEM, standard error of the mean; TUNEL, terminal transferase-mediated dUTP nick end-labeling;

\section{Introduction}

Chronic myelogenous leukemia (CML) is caused by Bcr-Abl, a fusion protein generated by a reciprocal translocation between chromosomes 9 and $22 .^{1} \mathrm{Bcr}-\mathrm{Abl}$ is a constitutively active tyrosine kinase phosphorylating a variety of substrates that are key elements of multiple signaling pathways, among others phosphatidylinositolol 3-kinase (PI3-K/Akt), and the mitogen-activated protein kinase (MAPK) pathway. ${ }^{2,3} \mathrm{Bcr}-\mathrm{Abl}$ thereby leads to a reduced growth factor dependency, ${ }^{4-6}$ alters adhesion properties to bone marrow stroma, ${ }^{7-9}$ protects cells from apoptosis in the absence of external growth factors, ${ }^{10-13}$ and leads to an increase of spontaneous and DNA damage-induced mutation frequency. ${ }^{14}$ Imatinib mesylate (STI571, Gleevec ${ }^{\circledR}$ ), a specific tyrosine kinase inhibitor of Bcr-Abl, has been used successfully for the treatment of CML. ${ }^{15}$ In vitro, imatinib blocks antiapoptotic functions of Bcr$\mathrm{Abl}$ and reverses growth factor independence. ${ }^{16}$ The molecular mechanisms underlying the induction of cell death by imatinib in Bcr-Abl-positive cells are incompletely understood. Imatinib causes downregulation of antiapoptotic $\mathrm{Bcl}-\mathrm{X}_{\mathrm{L}}$ and XIAP. ${ }^{17,18}$ Cell death upon imatinib exposure is also partially dependent on $\mathrm{p} 53$ function. ${ }^{19}$ In addition, activation of effector caspases also accompanies cell death induced by imatinib. ${ }^{20}$ Finally, very recent data show that imatinib induces a caspase-independent, necrosis-like programmed cell death mediated by a serine protease activity. ${ }^{21}$ However, blocking one of these pathways is not capable of completely inhibiting the cell death after treatment with imatinib. ${ }^{19,21}$ Therefore, it seems likely that different pathways exist in parallel which are involved in cell death caused by Bcr-Abl kinase inhibition.

Poly(ADP-ribosyl)ation (PAR) driven by the enzymatic activity of poly(ADP-ribose) polymerase (PARP) is a major mediator of cell death after exposure to a variety of DNA damage-inducing agents. ${ }^{22}$ PARP is rapidly activated by DNA strand breaks catalyzing the transfer of the ADP-ribose moiety from the co-enzyme $\mathrm{NAD}^{+}$to a number of nuclear acceptor proteins. $^{22}$ The $\mathrm{NAD}^{+}$pool is largely compartmentalized within the mitochondria, ${ }^{23}$ and the depletion of $\mathrm{NAD}^{+}$due to PARP activation might then cause alterations of the mitochondria. ${ }^{24}$ Aside from the established role of PARP in necrotic cell death after excessive DNA damage, precocious and transient PARP activation is also actively involved in apoptotic processes. In immortalized embryonic mouse fibroblasts, PARP has been shown to be essential for translocation of apoptosis-inducing factor (AIF), ${ }^{25}$ a mitochondrial proapoptotic protein that induces chromatin condensation and DNA fragmentation in a caspase-independent form of apoptosis. ${ }^{26}$ In this cellular system, the presence of a PARP inhibitor but not the inhibition of caspase activity completely prevents cell death. Therefore, it seems likely that PARP plays an essential role for DNA damage-induced apoptosis.

In addition to its role as a DNA damage sensor, PARP also binds to undamaged DNA structures ${ }^{27}$ and is involved in physiological regulation of cellular functions. Recent studies propose a role of PARP in the regulation of gene transcription. ${ }^{28}$ Moreover, experimental evidence has been published supporting the view that PARP-catalyzed PAR is involved in cell death processes other than DNA damage-induced cell 
death: Treatment of human squamous KB cancer cells with interferon $\alpha$ resulted in a stimulated PARP activity leading to an increasing PAR synthesis. ${ }^{29}$ We therefore hypothesized that PARP activity may play a role for imatinib-induced cell death in Bcr-Abl-positive cells.

\section{Results}

\section{Inhibition of Bcr-Abl with imatinib leads to a rapid and massive increase of PAR in human and murine Bcr-Abl-positive cell lines}

To investigate the effect of imatinib on PARP activation, different human and murine Bcr-Abl-expressing cell lines were incubated with imatinib for the indicated time points. In all cell lines, we observed a substantial and rapid increase of poly(ADP-ribosyl)ated proteins (Figure 1). The kinetics of PAR formation differed between the cell lines starting after 6$8 \mathrm{~h}$ in the two slower growing cell lines M07BA and MEG-01 (Figure 1a), and $2-4 \mathrm{~h}$ in the two fast proliferating cell lines BaF3BA (Figure 1b, left panel) and 32DBA (Figure 1c, left panel). The ribosylation pattern detected by Western blot analysis was comparable in all cell lines. To analyze whether imatinib-induced PAR formation reflects PARP activity, BaF3BA cells were preincubated with the pharmacological PARP inhibitor PJ34 ${ }^{30,31} 2 \mathrm{~h}$ prior to imatinib treatment. As shown in Figure 1b, the addition of PJ34 to the culture medium led to a complete inhibition of imatinib-induced PAR formation throughout the observed time period. In addition to the Bcr-Abl kinase, imatinib inhibits a variety of other tyrosine kinases such as c-Abl, the platelet-derived growth factor receptors (PDGFR $\alpha$ and $\beta$ ), ${ }^{32}$ and $\mathrm{c}-\mathrm{Kit}$, the receptor for stem cell factor. ${ }^{33}$ To clarify whether inhibition of Bcr-Abl kinase activity is responsible for PAR induction, we used a 32D cell line transfected with a mutated $b c r-a b l(B A)$ variant leading to complete imatinib resistance (32DBAT315I). ${ }^{34}$ No increase of PAR formation following imatinib treatment was detected in cells expressing the imatinib-resistant BA variant (Figure 1c, right panel).

\section{Inhibition of the PI3-K pathway but not the MAPK pathway is sufficient to induce PAR formation}

The MAPK arm of the Ras pathway and the PI3-K pathway are both pivotal for the antiapoptotic signaling of Bcr-Abl. ${ }^{35,36}$ Inhibition of Bcr-Abl kinase activity by imatinib delays both pathways in Bcr-Abl-positive cells (Figure $2 b$, upper panel), whereas imatinib had no effects on these pathways in Bcr-Ablnegative cells (data not shown). Therefore, we investigated whether inhibition of one of these pathways is sufficient to induce PAR formation. BaF3BA cells were cultured in the presence of the PI3-K inhibitors LY294002 and wortmannin, the $\mathrm{m}$-TOR inhibitor rapamycin, or the MAPK kinase inhibitor PD98059. As shown in Figure 2a, treatment with the PI3-K inhibitors LY249002 and wortmannin mimicked the imatinibinduced PAR formation. In contrast, PARP activity did not change significantly upon addition of the MAPK kinase inhibitor PD98059 or the $\mathrm{m}$-TOR inhibitor rapamycin along the same time period (Figure 2a). All inhibitors were effective in the BaF3BA cells, since the inhibitors elicited a significant reduction in phosphorylated Akt, S6 ribosomal protein, or p44 MAPK (Figure 2b). Neither treatment of cells with LY294002, wortmannin, or rapamycin nor treatment with PD98059 markedly induced apoptosis within the time frame of investigation (data not shown). These results indicate that Bcr-Abl inhibits PAR formation via the PI3-K pathway without participation of the $\mathrm{m}$-TOR arm, whereas modulation of the MAPK pathway is not responsible for the downregulation of PARP activity by Bcr-Abl.

\section{Induction of PAR subsequent to imatinib treatment precedes loss of integrity of mitochondrial membrane, Annexin $\mathrm{V}$ binding, and the appearance of DNA strand breaks}

DNA strand break formation has been considered to be an essential prerequisite for PARP activation. ${ }^{37}$ To examine whether imatinib-induced PARP activation depends on DNA damage, we compared the time course of PAR formation with the kinetics of cell death processes following imatinib treatment. We studied in parallel protein ribosylation, loss of mitochondrial membrane potential, Annexin $\mathrm{V}$ binding, DNA fragmentation, and PARP cleavage in imatinib-treated BaF3$B A$ cells at the indicated time points. As shown in Figure 3a, the amounts of poly(ADP-ribosyl)ated proteins increased before the other cell death signs came up. The maximum of PAR formation was detected $2 \mathrm{~h}$ after starting imatinib treatment, whereas the other classical apoptotic events showed only a minimal increase up to $4 \mathrm{~h}$ and then continuously progressed. In addition, there was no significant loss of ATP during the first $6 \mathrm{~h}$ (Figure $3 \mathrm{~b}$ ). To summarize, we observed a rapid formation of poly(ADP-ribose) polymers following imatinib treatment preceding other apoptotic events such as DNA strand break formation.

\section{Inhibition of PARP activity partially blocks imatinib-induced cell death and leads to an increased clonogenic survival of imatinib-treated cells}

It has been shown recently that PARP-catalyzed PAR formation plays the central role in $N$-methyl- $N$-nitro- $N$ nitrosoguanidine (MNNG)-induced apoptosis of immortalized mouse embryonic fibroblasts (MEFs). ${ }^{25}$ Pretreatment of MEFs with PARP inhibitors led to a complete prevention of MNNG-mediated cell death, whereas the general caspase inhibitor zVAD-fmk (zVAD) had no effect in this cellular system. ${ }^{25}$ To examine whether this PARP-mediated cell death plays also a role in imatinib-treated hematopoietic cells, we analyzed Annexin $\mathrm{V}$ binding and propidium iodide (PI) uptake following imatinib treatment in the presence or absence of PJ34. As shown in Table 1, inhibition of PARP by PJ34 led to a retardation of cell death process induced by imatinib: The Annexin $\mathrm{V}-/ \mathrm{PI}$ - cell fraction was significantly higher following PARP inhibition. However, the PJ34mediated protection was incomplete. Surprisingly, this was also true for cell death induced by the DNA-damaging agent MNNG in BaF3BA cells: The degree of PJ34-mediated protection from cell death after MNNG was comparable to 
a

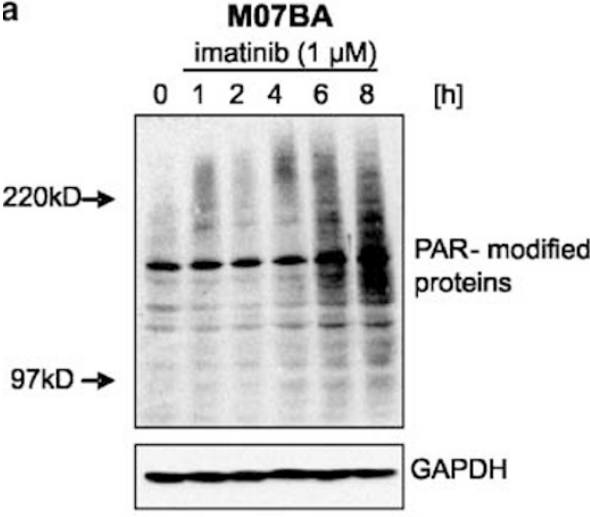

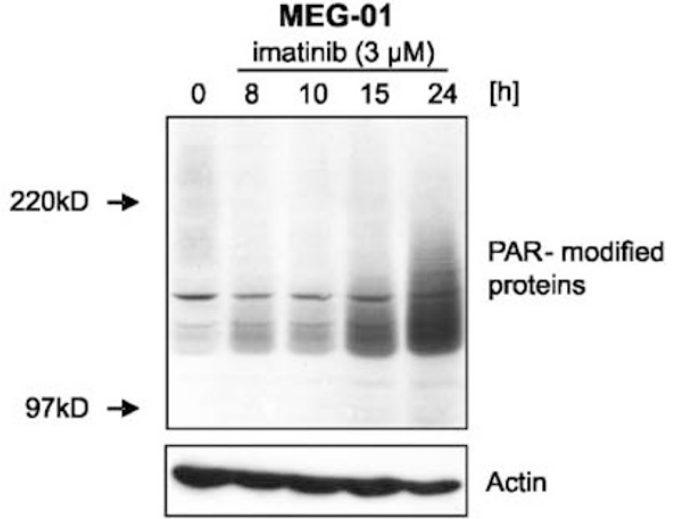

b

BaF3BA

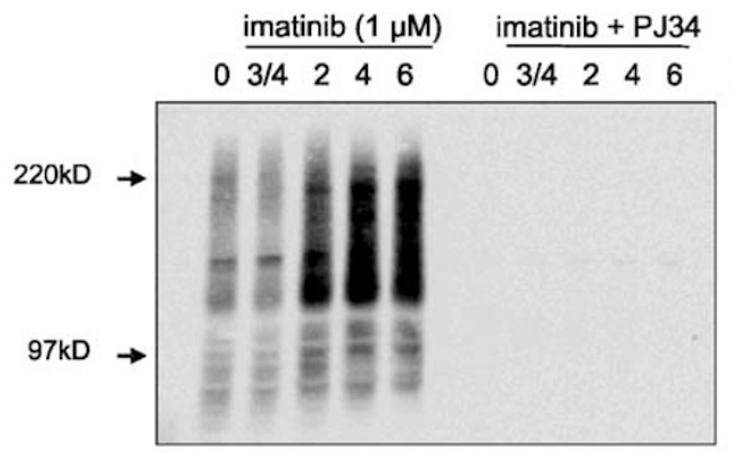

[h]

modified

proteins

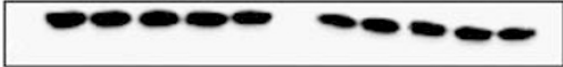

GAPDH

C

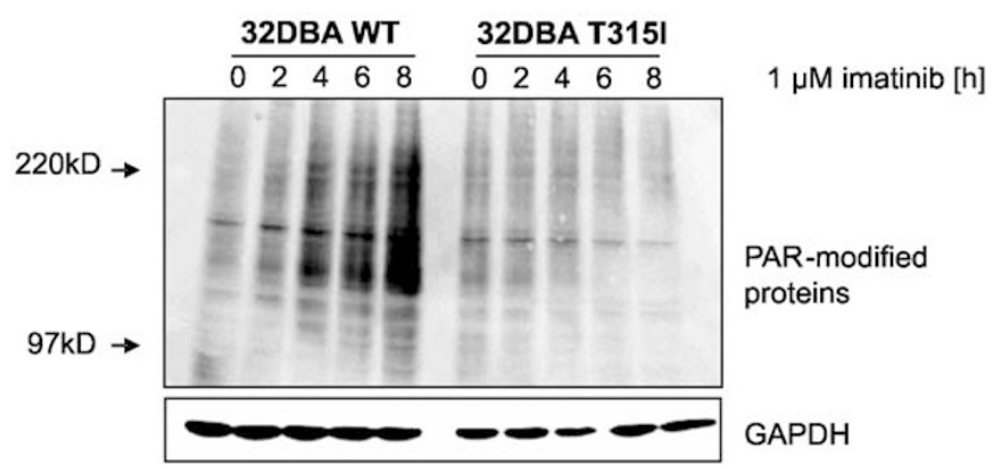

Figure 1 Poly(ADP-ribosyl)ation (PAR) is induced by imatinib treatment of Bcr-Abl-positive cells and is dependent on PARP activity. (a) M07BA and MEG-01 cells were treated with imatinib for the indicated time periods. Total extracts were prepared and electrophoretically separated. PAR was detected using a polyclonal antibody recognizing poly(ADP-ribose) polymers. Equal loading was controlled by reprobing with antibodies to glyceraldehyde-3-phosphate dehydrogenase (GAPDH) or $\beta$-actin. (b) BaF3BA cells cultured in the presence or absence of the PARP inhibitor PJ34 $(4 \mu \mathrm{M})$ with $1 \mu \mathrm{M}$ imatinib for the indicated time points were harvested and total cellular extracts were prepared. Equal amounts of proteins were electrophoretically separated prior to immunoblotting with PAR antibody. Equal loading was controlled by reprobing with an anti-GAPDH antibody. (c) 32DBA WT and the imatinib-resistant mutant 32DBA T315I were cultured with imatinib as indicated. Cellular extracts were prepared and equal amounts of proteins were electrophoretically separated prior to immunoblotting using PAR antibody. Equal loading was controlled by reprobing with an anti-GAPDH antibody

that observed after imatinib treatment. Therefore, in this hematopoietic cell system, cell death induced by both growth signal deprivation (imatinib) and DNA damage (MNNG) was only partially blocked by PARP inhibition. This is in contrast to the effect observed in MNNG-treated MEFs. Consistent with the data published by $\mathrm{Yu}$ et al., ${ }^{25}$ PJ34 completely blocks MNNG-induced toxicity in mouse fibroblasts (Table 1). Importantly, the concentration of PJ34 used throughout the experiments did not inhibit PI3-K or MAPK pathways (data not shown).

To further clarify the cellular consequences of PARP inhibition in imatinib-mediated cell death, we investigated DNA strand break formation and long-term survival of imatinib-treated cells in the presence or absence of PJ34. DNA strand break formation as revealed by TUNEL was significantly reduced by pharmacological inhibition of PARP 


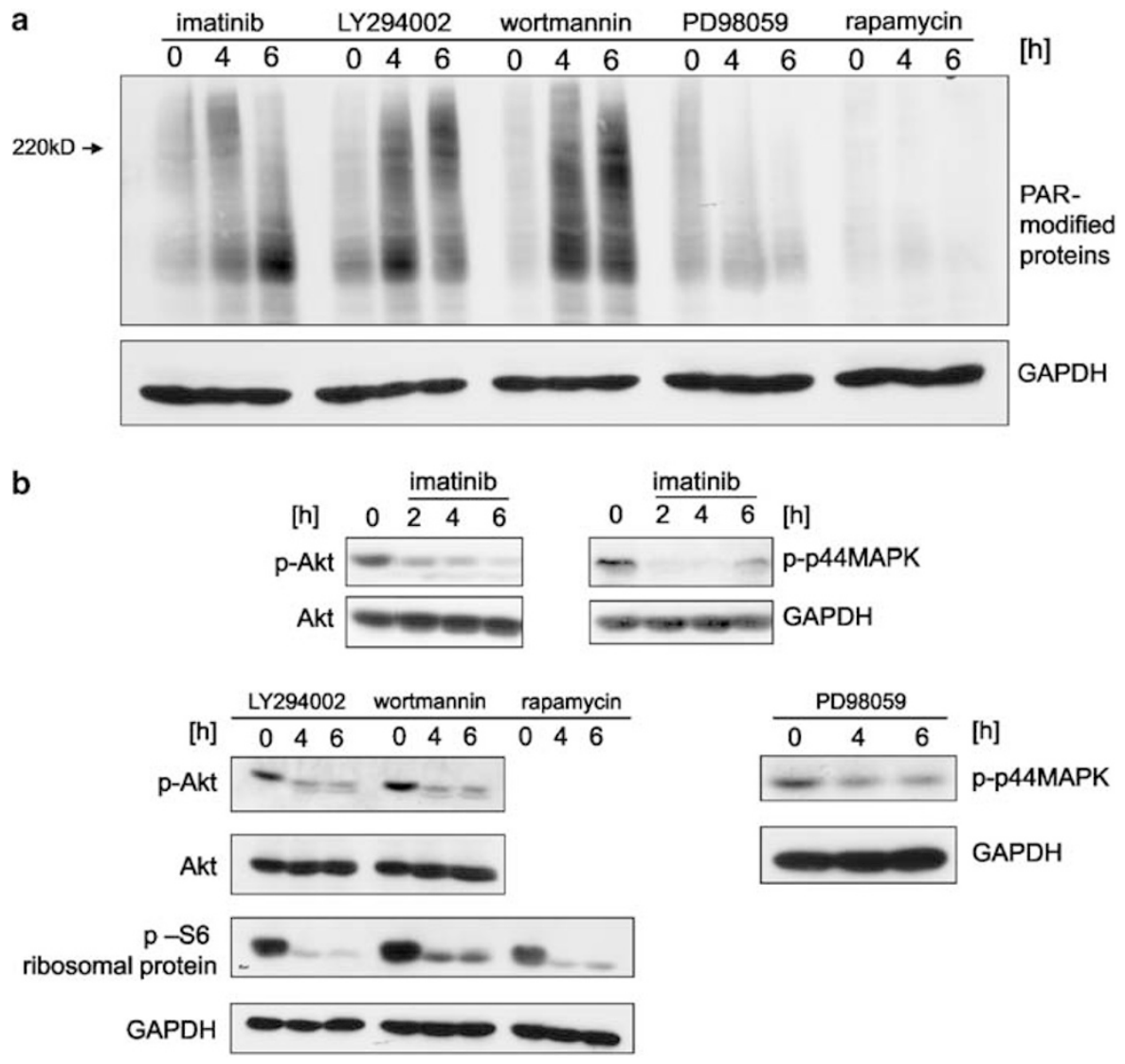

Figure 2 Influence of inhibition of PI3-K and MAPK pathways on PARP activity. (a) BaF3BA cells were cultured in the absence or presence of imatinib (1 $\mu$ M), LY294002 $(25 \mu \mathrm{M})$, wortmannin $(200 \mathrm{nM})$, PD98059 $(25 \mu \mathrm{M})$, and rapamycin $(10 \mathrm{ng} / \mathrm{ml})$ as indicated. Total cellular extracts were prepared at the time points indicated electrophoretically separated, and subjected to immunoblotting with antibodies against PAR, and anti-GAPDH. (b) Total cellular protein was prepared and subjected to Western blot analysis to elucidate the effects of inhibitor treatment on phosphorylation of the downstream targets Akt, S6 ribosomal protein, and p44MAPK

Table 1 Impact of PARP activity on imatinib and MNNG-induced cell death

\begin{tabular}{|c|c|c|c|c|c|c|}
\hline & \multicolumn{4}{|c|}{ BaF3BA } & \multicolumn{2}{|c|}{ MEF } \\
\hline & Imatinib & imatinib+PJ34 & MNNG & MNNG+PJ34 & MNNG & MNNG+PJ34 \\
\hline $\begin{array}{l}\text { Annexin } \mathrm{V}-/ \mathrm{PI}- \\
\text { Annexin } \mathrm{V}+/ \mathrm{PI}- \\
\text { Annexin } \mathrm{V+} / \mathrm{PI+}\end{array}$ & $\begin{array}{l}24.0 \pm 2.7 \\
10.8 \pm 2.0 \\
63.9 \pm 2.5\end{array}$ & $\begin{array}{l}38.9 \pm 3.2 \\
17.3 \pm 2.9 \\
41.8 \pm 3.0\end{array}$ & $\begin{array}{r}6.1 \pm 1.7 \\
9.2 \pm 3.7 \\
84.3 \pm 3.6\end{array}$ & $\begin{array}{l}18.0 \pm 2.8 \\
22.0 \pm 2.5 \\
59.6 \pm 3.2\end{array}$ & $\begin{array}{r}11.6 \pm 8.4 \\
7.3 \pm 0.4 \\
80.4 \pm 9.4\end{array}$ & $\begin{array}{r}87.9 \pm 0.7 \\
5.6 \pm 2.5 \\
6.2 \pm 2.1\end{array}$ \\
\hline
\end{tabular}

Flow cytometry analysis of BaF3BA exposed to imatinib ( $1 \mu \mathrm{M}, 15 \mathrm{~h}$; left columns), and with MNNG (0.15 mM, pulse-treated for 15 min, $15 \mathrm{~h}$ after treatment; middle columns) or MEFs pulse-treated with MNNG $(0.5 \mathrm{mM}$, pulse-treated for $15 \mathrm{~min}, 15 \mathrm{~h}$ after treatment; right columns) in the presence or absence of PARP inhibitor PJ34. Cells were stained with Annexin V-FITC to detect phosphatidylserine exposure and with PI to determine membrane integrity. Values are means \pm S.E.M. of three independent experiments.

both in BaF3BA and MEG-01 cells (Figure 4a). In addition, cells exhibiting a DNA content lower than $2 \mathrm{~N}$ indicative for imatinib-induced DNA fragmentation were reduced in the presence of PJ34 in BaF3BA (Figure 4b) and Meg-01 (not shown). To investigate whether this alteration of the death process has an impact on long-term survival of cells, we studied colony formation ability in BaF3BA and MEG-01 cells following pulse treatment with imatinib in the presence or absence of PJ34. After exposure to $1 \mu \mathrm{M}$ imatinib for $15 \mathrm{~h}$ a very small amount of BaF3BA cells survived in soft agar, whereas the addition of PJ34 led to a three times higher cloning efficiency (Figure 4c, left panel). Similar results were obtained in experiments with human MEG-01 cells following pulse treatment with $3 \mu \mathrm{M}$ imatinib for $24 \mathrm{~h}$ (Figure $4 \mathrm{c}$, right panel). Importantly, the surviving clones remained sensitive to imatinib (data not shown). Therefore, a selection process leading to a selective survival of imatinib-resistant cells is unlikely.

\section{Imatinib-induced cell death is dependent on at least two different pathways}

To elucidate the significance of the observed PARP-mediated cell death in comparison to the well-documented caspasedependent mitochondrial apoptotic pathway, we treated 
a
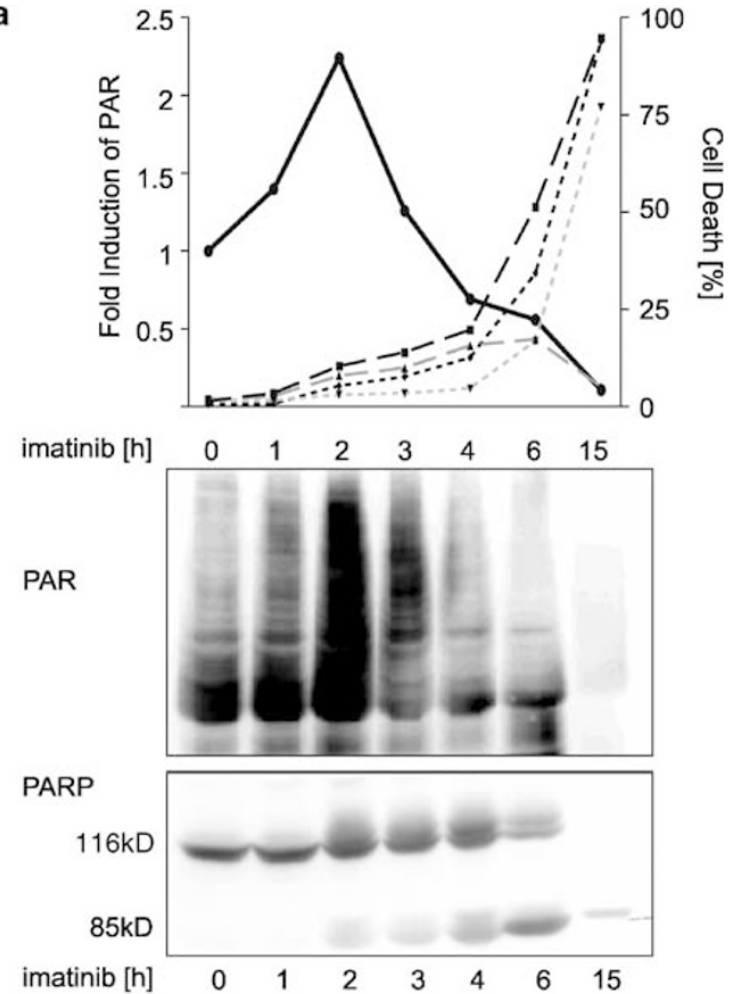

b

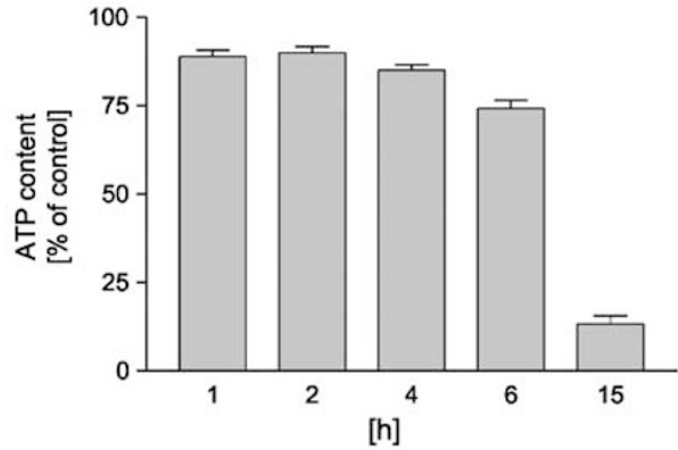

Figure 3 Poly(ADP-ribosyl)ation (PAR) exerts its regulatory function during the early phase of apoptosis and precedes DNA fragmentation. (a) Time course of loss of mitchondrial membrane potential (black dashed line), phosphatidylserine exposure (Annexin V +/PI- cells: gray dashed line; Annexin V+/PI + cells: gray dotted line), DNA fragmentation (black dotted line), PAR of nuclear proteins (black solid line), and PARP cleavage following imatinib treatment. Mitochondrial membrane depolarization was assessed by the loss of TMRM staining of mitochondria. Cells incubated for the indicated time points with $1 \mu \mathrm{M}$ imatinib were stained with TMRM $(50 \mathrm{nM})$, or Annexin V-FITC. Formation of DNA fragments in BaF3BA after imatinib treatment was measured by terminal transferase-mediated dUTP nick end-labelling (TUNEL) analysis as described in 'Material \& Methods'. The time course of imatinib-induced PAR synthesis and PARP cleavage were detected by Western blot analysis using an antibody to PAR and PARP, respectively. The induction of PAR was quantified by densitometry. (b) Time course of ATP concentration following imatinib treatment. Values are means \pm standard error of the mean (S.E.M.) of sextuples from three independent experiments

BaF3BA cells with imatinib alone or in combination with the appropriate inhibitors for $15 \mathrm{~h}$. The cytoprotective effect of the caspase inhibitor zVAD-fmk (zVAD) was comparable to that observed with PJ34. However, simultaneous inhibition of both caspases and PARP revealed an additive effect on cytoprotection against imatinib (Figure 5). Importantly, in contrast to PJ34, zVAD did not alter PAR formation and the concentration of $z V A D$ was sufficiently high to inhibit caspase 3 activity throughout these experiments (data not shown).

\section{Discussion}

This is the first report showing that imatinib induces PAR in Bcr-Abl-positive cells. Moreover, pharmacological inhibition of PARP activity partially prevents imatinib-induced cell death in hematopoietic Bcr-Abl-positive cells to an extent comparable to that observed, for example, after inhibition of caspase activation in the same cells.

PAR has been implicated in many important cellular processes such as DNA repair and replication, modulation of chromatin structure, and cell death. ${ }^{38}$ Aside from the established role of PARP activation in necrotic cell death, much interest is emerging to understand the precise role of PARP in apoptosis. PAR is known to be induced by stressors such as $\mathrm{H}_{2} \mathrm{O}_{2}$ or alkylating agents. ${ }^{22}$ In these processes, DNA damage has been considered to be an essential prerequisite for PARP activation. Importantly, DNA damage has not been implicated in the initiation of cell death induced by imatinib in Bcr-Abl-positive cells so far. Our results show that PAR of nuclear proteins starts very early after treatment with imatinib and clearly precedes the appearance of DNA fragmentation as assessed by TUNEL in our cell lines. In addition, DNA fragmentation is significantly reduced in cells treated with PJ34. Therefore, it is unlikely that the protein PAR observed in our experiments is simply a consequence of imatinib-induced DNA fragmentation.

The second novel aspect of our study is that PARP activation is part of the cell death machinery induced by imatinib in Bcr-Abl-positive cells. Interestingly, in hematopoietic cells this pathway seems to play a comparable role both in DNA damage-independent (inhibition of Bcr-Abl) and DNA damage-dependent (DNA alkylation) cell death: pretreatment of cells with PJ34 only partially inhibits cell death both induced by imatinib or DNA-alkylating agents. In contrast, PARP inhibition completely blocks MNNG-mediated cell death in other cellular systems like astrocytes ${ }^{39}$ and MEFs (our results and previous published data $^{25}$ ). Therefore, it has to be concluded that the choice between the different alternative and/or parallel cell death pathways not only depends on the stress stimulus but also on the cell type affected.

It has been reported previously that imatinib induces a caspase-dependent mitochondrial apoptosis. ${ }^{20,40}$ However, our results and other previously published data ${ }^{21}$ demonstrate that the broad caspase inhibitor zVAD fails to completely block imatinib-induced cell death indicating that both caspasedependent and -independent cell death pathways are activated. Our results show that both the PARP activation and the induction of caspases play a comparable role for the induction of cell death in imatinib-treated Bcr-Abl-positive cells. Inhibition of one of these pathways was not sufficient to completely block imatinib-induced cell death in our cell system. However, simultaneous inhibition of both caspase and PARP-dependent pathways had an additive cytoprotective effect suggesting that 

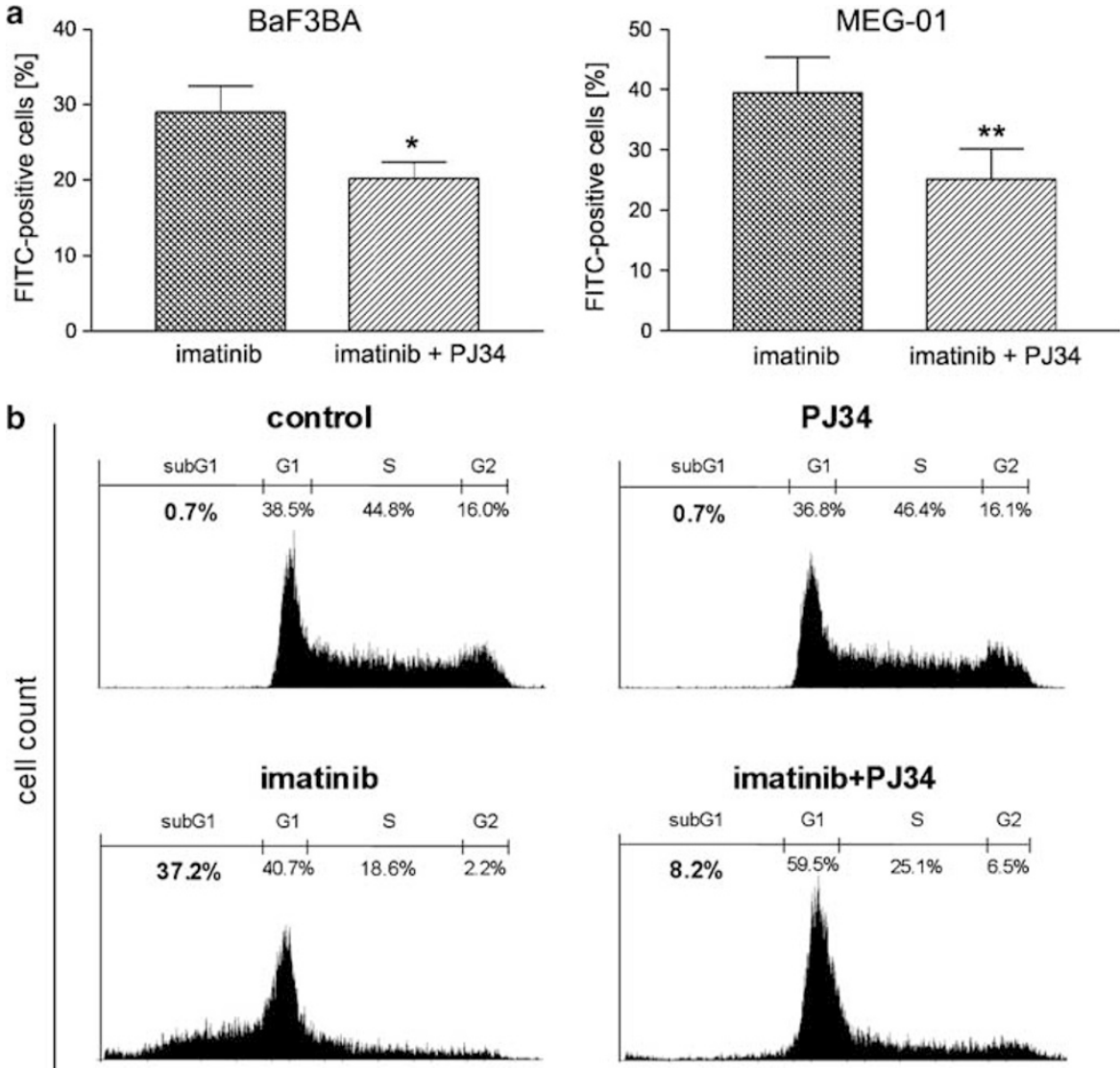

\section{PJ34}

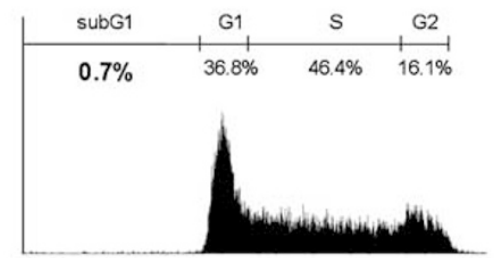

\section{imatinib+PJ34}

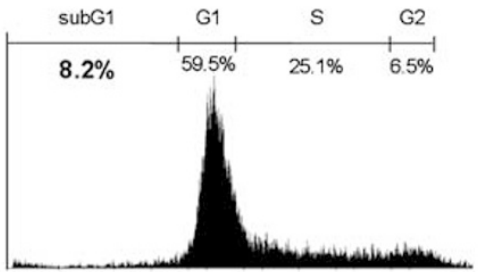

DNA content
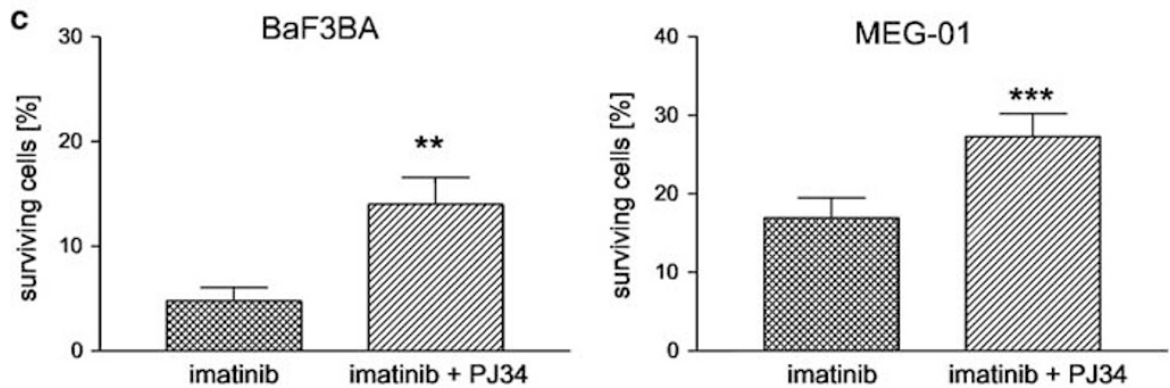

Figure 4 Pharmacological inhibition of PARP partially prevents DNA fragmentation and imatinib-induced cell death. (a) BaF3BA and MEG-01 cells were preincubated with $4 \mu \mathrm{M}$ PJ34 and subsequently treated with $1 \mu \mathrm{M}$ imatinib for $6 \mathrm{~h}$ (left panel) or $3 \mu \mathrm{M}$ imatinib for $24 \mathrm{~h}$ (right panel). The percentage of DNA fragmentation was determined by TUNEL assay. Values reflect the mean \pm S.E.M. of five (BaF3BA) and seven (MEG-01) independent experiments. The differences were significant as determined by two-sided paired Student's $t$-test $\left({ }^{*} P<0.05 ;{ }^{*} P<0.01\right)$. (b) Flow cytometry analysis of imatinib-induced cell cycle alterations in the presence or absence of $1 \mu \mathrm{M}(\mathrm{BaF} 3 \mathrm{BA})$ imatinib and PJ34 $(4 \mu \mathrm{M})$. The nuclear DNA content was analyzed by propidium iodide (PI) staining. (c) Effect of PARP inhibition on clonogenic survival of BaF3BA and MEG-01 cells in response to imatinib. Cells were pulse-treated with $1 \mu \mathrm{M}$ imatinib for $15 \mathrm{~h}$ (left panel) or $3 \mu \mathrm{M}$ for $24 \mathrm{~h}$ (right panel) in the presence or absence of PJ34 $(4 \mu \mathrm{M})$, resuspended in semisolid RPMI containing $0.3 \%$ agar and plated at a density of 100 cells per well in six-well plates. Cells were incubated for 7 days for BaF3BA or 14 days for MEG-01, respectively, and colonies larger than 50 cells were counted. Values reflect the mean + S.E.M. of eight (BaF3BA) and seven (MEG-01) independent experiments. The differences were significant as revealed by two-sided paired Student's $t$ test $\left({ }^{* \star} P<0.01 ;{ }^{* \star \star} P<0.001\right)$

these pathways coexist independent of each other. The discussion how overactivation of PARP leads to cell death is still controversial. The observation that PAR leads to a massive utilization of $\mathrm{NAD}^{+}$and subsequent consumption of ATP led to the 'suicide hypothesis'. ${ }^{41}$ However, direct evidence that PARP-dependent cell death bases only on energy depletion is still lacking. Imatinib did not lead to a significant loss of ATP content in our cell systems during the first hours arguing against the view that energy depletion might be sufficient for PARP-dependent cell death. Recent studies indicate that AIF may be a key mediator of cell death downstream of PARP activation. ${ }^{42}$ AIF translocates from the mitochondrial intermembrane space to the nucleus where it mediates DNA fragmentation and nuclear condensation. ${ }^{26}$ 


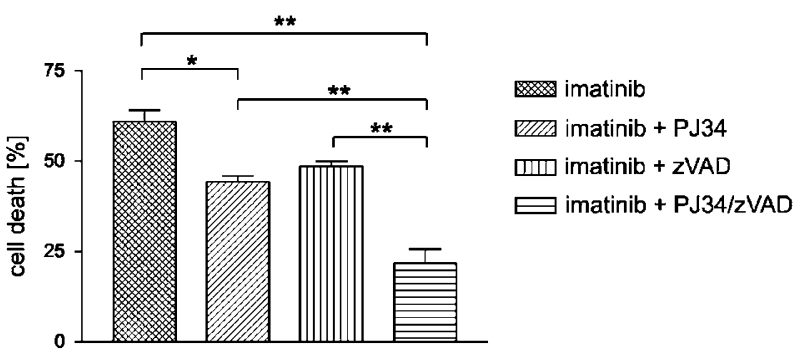

Figure 5 Imatinib induces at least two pathways leading to cell death. BaF3BA cells were pretreated with or without PJ34, ZVAD, or PJ34 + ZVAD and subsequently incubated with imatinib for $15 \mathrm{~h}$. Cell death is represented as percentage of PI-positive population. Data represent means + S.E.M. of five individual experiments. The differences were significant as revealed by two-sided paired Student's $t$-test $\left({ }^{\star} P<0.05 ;{ }^{*} P<0.01\right)$

However, it is completely unclear how PARP activity triggers the release of AIF. Furthermore, it is controversial whether caspase activity is required for AIF release. ${ }^{43,44}$ At early time points we did not observe AIF translocation from the mitochondria to the nucleus in BaF3 cells after imatinib treatment (data not shown). This is consistent with recently published results showing that imatinib does not induce AIF translocation in Bcr-Abl-positive BV173 cells. ${ }^{21}$ Further studies are required to understand the mechanisms how PARP-mediated PAR triggers mitochondrial processes and cell death in cells treated with DNA-damaging agents or imatinib.

The imatinib effect on PAR formation is restricted to cells expressing imatinib sensitive Bcr-Abl, indicating that the kinase activity of Bcr-Abl prevents PAR. Importantly, inhibition of PI3-K was sufficient to induce PAR formation to a comparable extent to that observed with imatinib. Although LY294002 and wortmannin are known as inhibitors of the PI3$K$ pathway, they also inhibit several other enzymes involved in cell cycle regulation and DNA repair, including ATM, ATR, ${ }^{45}$ and DNA-PK. ${ }^{46}$ From our data, it cannot be ruled out that inhibition of these enzymes may induce PAR formation. However, there is no evidence that imatinib influences the activity of these DNA damage sensors nor have these enzymes been implicated in imatinib-induced cell death so far. Therefore, it is more likely that the inhibition of the PI3-K pathway is responsible for both LY294002/wortmannin and imatinib-induced PAR formation. At this point, it is important to mention that treatment of cells with LY294002/wortmannin for up to $6 \mathrm{~h}$ did not induce cell death. This is in contrast to the effect seen with imatinib. Therefore, PARP-induced ribosylation seems to be a prerequisite but is not sufficient to induce cell death in imatinib-treated Bcr-Abl-positive cells. This suggests that beside PAR a second (yet unknown) signal seems to be essential for the PARP-dependent cell death execution. The evidence that PI3-K directly or indirectly inhibits one of these signals, namely PAR, may be of clinical importance: inhibition of PI3-K and thereby induction of PAR may possibly sensitize tumor cells for clinically relevant drugs. Many of the known downstream effects of PI3-K are mediated through Akt. ${ }^{47}$ Akt interacts with a wide range of downstream effectors affecting cell proliferation, cell growth, and survival. ${ }^{48}$ Most of the known targets of Akt become inactivated upon phosphorylation. ${ }^{49}$ It remains to be elucidated if PARP is directly or indirectly inhibited by PI3-K signaling.

In conclusion, our data suggest a direct role for PAR in the cell death processes subsequent to inhibition of Bcr-Abl. We further demonstrate that caspase-dependent and caspaseindependent cell death pathways are activated after withdrawal of survival signals provided by Bcr-Abl. Optimal induction of cell death by imatinib requires the function of both pathways. Pharmacological manipulation of PARP and its antagonist may, therefore, serve as a strategy to modulate the antineoplastic efficacy not only of imatinib but also of radiotherapy and chemotherapy.

\section{Materials and Methods}

\section{Cell culture}

BaF3BA (expressing p185bcr-ab), kindly provided by J Duyster (Munich, Germany), were generated by transforming the murine factor-dependent pro-B cell line BaF3 with pSLXBcr-Abl. The factor-independent murine 32DBA oligoclonal cell line (expressing p210bcr-abl) was generated by transfecting the parental $32 \mathrm{D}$ cells with the retroviral vector Mig-p210 $0^{50}$ or Mig-p210-T315I. The Bcr-Abl-positive human cell line M07BA was kindly provided by $\mathrm{M}$ Hallek (Munich, Germany) and generated by electroporation of M07e cells with the pGD210 plasmid. The human cell line MEG$01,{ }^{51}$ a Philadelphia chromosome-positive $\left(\mathrm{Ph}^{+}\right)$megakaryoblastic cell line, was purchased from DSMZ cell culture collection (DSMZ, Braunschweig, Germany). Human cell lines were cultivated in RPMI 1640 (Biochrom, Berlin, Germany) complemented with 10\% fetal calf serum and glutamine. Experiments with $\mathrm{BaF} 3$ and $32 \mathrm{D}$ cells were performed in serum-free medium (UltraCULTURE, Bio Whittaker, Belgium).

\section{Reagents}

Imatinib mesylate (STI571, Gleevec ${ }^{\circledR}$ ) was kindly provided by Novartis Pharma AG (Basel, Switzerland). A stock solution $(10 \mathrm{mg} / \mathrm{ml})$ was prepared by dissolving the compound in DMSO: $\mathrm{H}_{2} \mathrm{O}(1: 1)$ and was stored at $-20^{\circ} \mathrm{C}$. Imatinib was used at a concentration of $1 \mu \mathrm{M}$ for BaF3BA, 32DBA, and M07BA cells and $3 \mu \mathrm{M}$ for MEG-01 cells. Other reagents were used at the following concentrations: PARP inhibitor PJ34, $4 \mu \mathrm{M}$; PI3-K inhibitor wortmannin, $200 \mathrm{nM}$; PI3-K inhibitor LY294002, $25 \mu \mathrm{M}$; MEK inhibitor PD98059, $25 \mu \mathrm{M}$; m-TOR inhibitor rapamycin, $10 \mathrm{ng} /$ $\mathrm{mL}$; broad caspase inhibitor zVAD, $50 \mu \mathrm{M}$. The inhibitors were obtained from Calbiochem (Merck, Darmstadt, Germany) with the exception of zVAD (Bachem, Bubendorf, Switzerland) and dissolved in DMSO with the exception of $\mathrm{PJ} 34\left(\mathrm{H}_{2} \mathrm{O}\right)$.

For combination of PJ34, zVAD, and imatinib, cells were incubated with $\mathrm{PJ} 34$ and $\mathrm{ZVAD}$ for $2 \mathrm{~h}$ prior to imatinib.

\section{Protein extraction to analyze basal and stimulated PAR levels}

Whole-cell pellets were resuspended in $200-250 \mu$ of a reducing lysis buffer containing $62.5 \mathrm{mM}$ Tris- $\mathrm{HCl}(\mathrm{pH} 6.8), 6 \mathrm{M}$ urea, $5 \% \beta$ mercapthoethanol, $2 \%$ SDS with proteases inhibitors (Complete, Roche Diagnostics $\mathrm{GmbH}$, Mannheim, Germany). To break out-coming DNA, the viscous solution was sonicated on ice for $20 \mathrm{~s}$. Samples were heated at $65^{\circ} \mathrm{C}$ for $15 \mathrm{~min}$ before loading on a $7.5 \%$ SDS-polyacrylamide gel. 


\section{Analysis of protein expression}

Proteins were transferred to nitrocellulose membranes (Schleicher \& Schuell, Bioscience GmbH, Dassel, Germany) for Western blot analysis. The blots were blocked in $5 \%$ nonfat dry milk in TBS-Tween and incubated with PAR antibody at 1:10000 dilution (anti-PAR, Alexis ${ }^{\circledR}$ Biochemicals, Qbiogene Inc., Carlsbad, CA, USA) recognizing poly(ADP-ribose) of 6100 bases in size. Afterwards, blots were incubated with secondary antibody (goat anti-rabbit) conjugated to horseradish peroxidase (diluted 1: 10000 ; Jackson ImmunoResearch, West Grove, PA, USA) and bound antibodies were detected by chemiluminescence (Pierce Biotechnology, Rockford, IL, USA). Equal loading was controlled by reprobing with antiGAPDH antibody (1: 10000 , Biodesign, Kennebunk, ME, USA) or anti- $\beta$ actin antibody (1:5000, Sigma, Taufkirchen, Germany) were used as a loading control.

PARP-1 protein expression was analyzed in BaF3BA using the monclonal mouse anti-poly(APD-ribose) polymerase antibody (Zymed ${ }^{\circledR}$ Laboratories Inc., San Francisco, CA, USA). Western blot analysis was performed, as described above.

\section{Cell extract preparation and Western blot analysis of phosphorylated proteins}

Extracts were prepared as described previously. ${ }^{19}$ One hundred $\mu \mathrm{g}$ Protein/lane was run on $7.5 \%$ SDS-polyacrylamide gel and then transferred to nitrocellulose membranes (Schleicher \& Schuell, Bioscience $\mathrm{GmbH}$, Dassel, Germany) using a semidry transfer system (BioRad, Hercules, CA, USA). The membranes were blocked, stained with antibodies of interest (anti-phospho-Akt, anti-Akt, anti-phosphop44MAPK, anti-phospho-S6-ribosomal protein) as recommended by the manufacturer (Cell Signaling, Beverly, MA, USA) and visualized by chemiluminescence (Pierce Biotechnology, Rockford, IL, USA).

\section{Colony-forming ability assay}

Following pulse-treatment with imatinib, cells were resuspended in semisolid RPMI containing $0.3 \%$ agar and plated at a density of 100 cells per well in six-well plates. Cells were then incubated for 7 days (BaF3BA) or 14 days (MEG-01). Colonies larger than 50 cells were counted.

\section{Detection of apoptosis}

The translocation of phosphatidylserine residues from the inner to the outer side of plasma membrane was assessed by FITC-conjugated Annexin V staining (Pharmingen, San Diego, CA, USA). The staining was performed according to the manufacturers' instructions. The staining solution contains PI (a red DNA-binding fluorochrom) to identify cells that have lost their membrane integrity. Cells were analyzed by flow cytometry. Mitochondrial membrane potential was determined using Tetramethylrhodamine Methylester staining (TMRM, Molecular Probes Inc., Eugene, OR, USA). Cells were harvested and washed with PBS once and then loaded with $50 \mathrm{nM}$ TMRM and incubated for $20 \mathrm{~min}$ at $37^{\circ} \mathrm{C}$. TMRM staining was analyzed by FACScan and CellQuest software (Becton Dickinson, San Jose, CA, USA).

\section{Cell cycle analyses}

After treatment, cells were pelleted and fixed in $70 \%$ ethanol at $4^{\circ} \mathrm{C}$ over night. Next day, cells were stained as described previously ${ }^{52}$ and cell cycle analyses were performed by determination of DNA content using FACScan (Becton Dickinson).

\section{FITC-TUNEL Flow cytometric assay}

Apoptotic DNA strand breaks were measured by labeling with FITC-dUTP using terminal deoxynucleotidyltransferase purchased from "In Situ Cell Detection Kit" (Roche, Mannheim, Germany). In brief, cells were washed in PBS, fixed for $30 \mathrm{~min}$ in $4 \%$ paraformaldehyde, and permeabilized in $0.1 \%$ sodium citrate, $0.1 \%$ Triton $X-100$ for 2 min on ice. Cells washed in PBS for two times and incubated for $60 \mathrm{~min}$ at $37^{\circ} \mathrm{C}$ with $50 \mu$ of TUNEL reaction mixture. Cells were then washed in PBS twice and analyzed for FITC fluorescence using FACScan (Becton Dickinson).

\section{Determination of ATP}

For ATP determination, 10000 cells were lysed in a cell lysis reagent (DCS Innovative Diagnostik-Systeme, Hamburg, Germany). ATP content was determined according to the manufacturer's instructions (DCS Innovative Diagnostik-Systeme, Hamburg, Germany). The reconstituted buffer containing the Luciferin and Luciferase was mixed with cell lysate and luminescence was analyzed in an ELISA reader.

\section{Statistics}

Data are expressed as S.E. M. Changes in paired samples (treatment with imatinib alone versus preincubation with PJ34 and subsequent treatment with imatinib) were analyzed using two-sided paired Student's $t$-test.

\section{Acknowledgements}

We thank $\mathrm{K}$ Gawronski for technical assistance. We thank Dr. E Buchdunger (Novartis Pharma AG, Basel, Switzerland) for the generous gift of imatinib mesylate (STI571, Gleevec $\left.{ }^{\mathbb{R}}\right)$. Dr. Justus Duyster and Dr. Michael Hallek kindly provided the Bcr-Abl-positive BaF3 and M07 cells. We also thank Dr. Elke Kleideiter and Dr. Benny Abraham for critical reading of the manuscript. Research Grants and other Financial Support: This work was financially supported by the Robert Bosch foundation project no. 02-1/03. A. Moehring is supported by a stipend from the Robert Bosch foundation.

\section{References}

1. Rowley JD (1973) Letter: a new consistent chromosomal abnormality in chronic myelogenous leukaemia identified by quinacrine fluorescence and Giemsa staining. Nature 243: 290-293

2. Chopra R, Pu QQ and Elefanty AG (1999) Biology of BCR-ABL. Blood Rev. 13: 211-229

3. Steelman LS, Pohnert SC, Shelton JG, Franklin RA, Bertrand FE and McCubrey JA (2004) JAK/STAT, Raf/MEK/ERK, PI3K/Akt and BCR-ABL in cell cycle progression and leukemogenesis. Leukemia 18: 189-218

4. McLaughlin J, Chianese E and Witte ON (1987) In vitro transformation of immature hematopoietic cells by the P210 BCR/ABL oncogene product of the Philadelphia chromosome. Proc. Natl. Acad. Sci. USA 84: 6558-6562

5. Daley GQ and Baltimore D (1988) Transformation of an interleukin 3dependent hematopoietic cell line by the chronic myelogenous leukemiaspecific P210bcr/abl protein. Proc. Natl. Acad. Sci. USA 85: 9312-9316

6. Lugo TG and Witte ON (1989) The BCR-ABL oncogene transforms Rat-1 cells and cooperates with v-myc. Mol. Cell. Biol. 9: 1263-1270 
7. Verfaillie CM, McCarthy JB and McGlave PB (1992) Mechanisms underlying abnormal trafficking of malignant progenitors in chronic myelogenous leukemia. Decreased adhesion to stroma and fibronectin but increased adhesion to the basement membrane components laminin and collagen type IV. J. Clin. Invest. 90: $1232-1241$

8. Gordon MY, Dowding CR, Riley GP, Goldman JM and Greaves MF (1987) Altered adhesive interactions with marrow stroma of haematopoietic progenitor cells in chronic myeloid leukaemia. Nature 328: 342-344

9. Bazzoni G, Carlesso N, Griffin JD and Hemler ME (1996) Bcr/Abl expression stimulates integrin function in hematopoietic cell lines. J Clin Invest. 98: 521-528

10. Bedi A, Zehnbauer BA, Barber JP, Sharkis SJ and Jones RJ (1994) Inhibition of apoptosis by BCR-ABL in chronic myeloid leukemia. Blood 83: 2038-2044

11. Laneuville P. Timm M and Hudson AT (1994) Bcr/abl expression in 32D cl3(G) cells inhibits apoptosis induced by protein tyrosine kinase inhibitors. Cancer Res. 54: 1360-1366

12. Sanchez-Garcia I and Martin-Zanca D (1997) Regulation of Bcl-2 gene expression by BCR-ABL is mediated by Ras. J. Mol. Biol. 267: 225-228

13. van der Kuip H, Goetz AW, Miething C, Duyster J and Aulitzky WE (2001) Adhesion to fibronectin selectively protects Bcr-Abl+ cells from DNA damageinduced apoptosis. Blood 98: 1532-1541

14. van der Kuip H, Moehring A, Wohlbold L, Miething C, Duyster J and Aulitzky WE (2004) Imatinib mesylate (STI571) prevents the mutator phenotype of BcrAbl in hematopoietic cell lines. Leuk. Res. 28: 405-408

15. Kurzrock R, Kantarjian HM, Druker BJ and Talpaz M (2003) Philadelphia chromosome-positive leukemias: from basic mechanisms to molecular therapeutics. Ann. Intern. Med. 138: 819-830

16. Druker BJ, Tamura S, Buchdunger E, Ohno S, Segal GM, Fanning S, Zimmermann $J$ and Lydon NB (1996) Effects of a selective inhibitor of the Abl tyrosine kinase on the growth of Bcr-Abl positive cells. Nat. Med. 2: 561-566

17. Oetzel C, Jonuleit T, Gotz A, van der Kuip H, Michels H, Duyster J, Hallek M and Aulitzky WE (2000) The tyrosine kinase inhibitor CGP 57148 (ST1 571) induces apoptosis in BCR-ABL-positive cells by down-regulating BCL-X. Clin. Cancer Res. 6: 1958-1968

18. Fang G, Kim CN, Perkins CL, Ramadevi N, Winton E, Wittmann $S$ and Bhalla KN (2000) CGP57148B (STI-571) induces differentiation and apoptosis and sensitizes Bcr-Abl-positive human leukemia cells to apoptosis due to antileukemic drugs. Blood 96: 2246-2253

19. Goetz AW, van der Kuip H, Maya R, Oren M and Aulitzky WE (2001) Requirement for Mdm2 in the survival effects of Bcr-Abl and interleukin 3 in hematopoietic cells. Cancer Res. 61: 7635-7641

20. Dan S, Naito M and Tsuruo T (1998) Selective induction of apoptosis in Philadelphia chromosome-positive chronic myelogenous leukemia cells by an inhibitor of BCR-ABL tyrosine kinase, CGP 57148 . Cell Death Differ. 5: $710-715$

21. Okada M, Adachi S, Imai T, Watanabe K, Toyokuni SY, Ueno M, Zervos AS, Kroemer $G$ and Nakahata T (2004) A novel mechanism for imatinib mesylateinduced cell death of BCR-ABL-positive human leukemic cells: caspaseindependent, necrosis-like programmed cell death mediated by serine protease activity. Blood 103: 2299-2307

22. D'Amours D, Desnoyers S, D'Silva I and Poirier GG (1999) Poly(ADPribosyl)ation reactions in the regulation of nuclear functions. Biochem. J. 342: 249-268

23. Di Lisa F, Menabo R, Canton M, Barile M and Bernardi $P$ (2001) Opening of the mitochondrial permeability transition pore causes depletion of mitochondrial and cytosolic NAD+ and is a causative event in the death of myocytes in postischemic reperfusion of the heart. J. Biol. Chem. 276: 2571-2575

24. Virag L, Salzman AL and Szabo C (1998) Poly(ADP-ribose) synthetase activation mediates mitochondrial injury during oxidant-induced cell death. J Immunol. 161: 3753-3759

25. Yu SW, Wang H, Poitras MF, Coombs C, Bowers WJ, Federoff HJ, Poirier GG Dawson TM and Dawson VL (2002) Mediation of poly(ADP-ribose) polymerase-1-dependent cell death by apoptosis-inducing factor. Science 297: 259-263

26. Susin SA, Lorenzo HK, Zamzami N, Marzo I, Snow BE, Brothers GM, Mangion J, Jacotot E, Costantini P, Loeffler M, Larochette N, Goodlett DR, Aebersold R, Siderovski DP, Penninger JM and Kroemer G (1999) Molecular characterization of mitochondrial apoptosis-inducing factor. Nature 397: 441-446
27. Soldatenkov VA and Potaman VN (2004) DNA-binding properties of poly(ADP-ribose) polymerase: a target for anticancer therapy. Curr Drug Targets 5: 357-365

28. Kraus WL and Lis JT (2003) PARP goes transcription. Cell 113: 677-683

29. Quesada P, Malanga M, Di Meglio S, De Lorenzo S, Fabbrocini A, Garbi C, Bianco AR and Pepe $S$ (2003) Recombinant IFN-alpha2b treatment activates poly (ADPR) polymerase-1 (PARP-1) in KB cancer cells. Eur. J. Cancer 39: 2103-2109

30. Southan GJ and Szabo C (2003) Poly(ADP-Ribose) polymerase inhibitors. Curr. Med. Chem. 10: 321-340

31. Beneke S, Diefenbach J and Bürkle A (2004) Poly(ADP-ribosyl)ation inhibitors: promising drug candidates for a wide variety of pathophysiologic conditions. Int. J. Cancer 111: 813-818

32. Buchdunger E, Cioffi CL, Law N, Stover D, Ohno-Jones S, Druker BJ and Lydon NB (2000) Abl protein-tyrosine kinase inhibitor STI571 inhibits in vitro signal transduction mediated by c-kit and platelet-derived growth factor receptors. J. Pharmacol. Exp. Ther. 295: 139-145

33. Heinrich MC, Griffith DJ, Druker BJ, Wait CL, Ott KA and Zigler AJ (2000) Inhibition of c-kit receptor tyrosine kinase activity by STI 571 , a selective tyrosine kinase inhibitor. Blood 96: 925-932

34. von Bubnoff N, Schneller F, Peschel C and Duyster J (2002) BCR-ABL gene mutations in relation to clinical resistance of Philadelphia-chromosome-positive leukaemia to STI571: a prospective study. Lancet 359: 487-491

35. Skorski T, Bellacosa A, Nieborowska-Skorska M, Majewski M, Martinez R, Choi JK, Trotta R, Wlodarski P, Perrotti D, Chan TO, Wasik MA, Tsichlis PN and Calabretta B (1997) Transformation of hematopoietic cells by BCR/ABL requires activation of a PI-3K/Akt-dependent pathway. EMBO J. 16:6151-6161

36. Woessmann W and Mivechi NF (2001) Role of ERK activation in growth and erythroid differentiation of K562 cells. Exp. Cell Res. 264: 193-200

37. Ame JC, Jacobson EL and Jacobson MK (2000) ADP-ribose polymer metabolism. In From DNA damage and Stress Signaling to Cell Death: Poly(ADP-ribosyl)ation reactions, de Murcia G, Shall S (eds). (New York: Oxford University Press) pp. 1-34

38. Burkle A (2001) Physiology and pathophysiology of poly(ADP-ribosyl)ation. BioEssays 23: 795-806

39. Alano CC, Ying W and Swanson RA (2004) Poly(ADP-ribose) polymerase-1mediated cell death in astrocytes requires NAD+ depletion and mitochondrial permeability transition. J. Biol. Chem. 279: 18895-18902

40. Mow BM, Chandra J, Svingen PA, Hallgren CG, Weisberg E, Kottke TJ, Narayanan VL, Litzow MR, Griffin JD, Sausville EA, Tefferi A and Kaufmann SH (2002) Effects of the Bcr/abl kinase inhibitors STI571 and adaphostin (NSC 680410) on chronic myelogenous leukemia cells in vitro. Blood 99: 664-671

41. Berger NA (1985) Poly(ADP-ribose) in the cellular response to DNA damage. Radiat. Res. 101: 4-15

42. Hong SJ, Dawson TM and Dawson VL (2004) Nuclear and mitochondrial conversations in cell death: PARP-1 and AIF signaling. Trends Pharmacol. Sci. 5: $259-264$

43. Arnoult D, Gaume B, Karbowski M, Sharpe JC, Cecconi F and Youle RJ (2003) Mitochondrial release of $\mathrm{AIF}$ and EndoG requires caspase activation downstream of Bax/Bak-mediated permeabilization. EMBO J. 22: 4385-4399

44. Penninger JM and Kroemer G (2003) Mitochondria, AlF and caspasesrivaling for cell death execution. Nat Cell Biol. 5: 97-99

45. Banin S, Moyal L, Shieh S, Taya Y, Anderson CW, Chessa L, Smorodinsky NI, Prives C, Reiss Y, Shiloh Y and Ziv Y (1998) Enhanced phosphorylation of p53 by ATM in response to DNA damage. Science 281: 1674-1677

46. Fukuchi K, Watanabe H, Tomoyasu S, Ichimura S, Tatsumi K and Gomi K (2000) Phosphatidylinositol 3-kinase inhibitors. Wortmannin or LY294002, inhibited accumulation of p21 protein after irradiation by stabilization of the protein. Biochim. Biophys. Acta. 1496: 207-220

47. Staal SP (1987) Molecular cloning of the akt oncogene and its human homologues AKT1 and AKT2: amplification of AKT1 in a primary human gastric adenocarcinoma. Proc. Natl. Acad. Sci. USA 84: 5034-5037

48. Vivanco I and Sawyers CL (2002) The phosphatidylinositol 3-kinase AKT pathway in human cancer. Nat. Rev. Cancer 2: 489-501

49. Cantley LC (2002) The phosphoinositide 3-kinase pathway. Science 296: 1655-1657

50. Pear WS (1998) Efficient and rapid induction of a chronic myelogenous leukemia- like myeloproliferative disease in mice receiving P210 bcr/abltransduced bone marrow. Blood 92: 3780-3792 
51. Ogura M, Morishima $\mathrm{Y}$, Ohno R, Kato $\mathrm{Y}$, Hirabayashi N, Nagura $\mathrm{H}$ and Saito $\mathrm{H}$ (1985) Establishment of a novel human megakaryoblastic leukemia cell line, MEG-01, with positive Philadelphia chromosome. Blood 66: 1384-1392
52. Jonuleit $\mathrm{T}$, van der Kuip $\mathrm{H}$, Miething $\mathrm{C}$, Michels $\mathrm{H}$, Hallek $\mathrm{M}$, Duyster $\mathrm{J}$ and Aulitzky WE (2000) Bcr-Abl kinase down-regulates cyclin-dependent kinase inhibitor p27 in human and murine cell lines. Blood 96: 1933-1939 